\title{
Ethics, Globalization, and the Role Educators Play
}

\author{
By Blaine T. Garfolo* \\ Barbara L'Huillier'
}

This paper questions the role educators' play in sustaining, promoting, and teaching the globalization business model in spite of the uneven privilege and distress that accompanies associated practices. Proponents of this business model claim it is based on democratic and capitalist principles promoting individual freedoms and equal opportunities. As teachers of the next generation of business functionaries we need to seek ways of engagement that extend us beyond harnessing extant flawed business models devoid of teleological ethical theory into mainstream management education. We argue that as educators we are implicated in maintaining a system that has a built-in willingness to tolerate sacrifice and distress of the most vulnerable of our world's citizens. It is a system that is feeding the growing disparity of wealth and influence and ultimately exists to serve the interests of the minority elite. We suggest that one way to address the "dark side" of globalization is to have ethics and ethical awareness at the forefront of what we teach our business graduates.

Keywords: education, ethics, globalization, MBA Programs.

\section{Introduction}

To postulate that we are in an era of de-colonization is perhaps to succumb to a gross underestimation of the nature of the problem, its historical structure and economic causes (Garfolo \& L'Huillier, 2014a). Without an analysis of both power and of sustainability that is in vogue in much management discourse, we may well be fooled into a sense of dangerous optimism, using "dangerous" as Bourdieu (1998) defines the term, a normalization of the logic of markets that encroaches on everything that Deetz (1992) calls "the life world".

Those in academia are in a unique position to influence future business and political leaders by what we teach and how we teach it. As academicians we have been willing to teach ethics in our business curriculum. However, we can tell you without hesitation that a business education is not just about knowledge and cognitive skills. It is also about a sense of humanity and an understanding that the role of business is not "just" business (L'Huillier, 2013). Humanity stresses the concept of basic human dignity for all.

Globalization is a process that results in an ever increasing interdependency of economies, societies and political systems resulting in what McGrew (2005), Portes (2000), Beck (2000), Held, McGrew, Goldblatt and

\footnotetext{
${ }^{*}$ Emeritus Associate Professor, Northwestern Polytechnic University, USA.

$\uparrow$ Associate Chair - Department of Accounting and Finance, Prince Mohammad Bin Fahd University, Kingdom of Saudi Arabia.
} 
Perraton (1999), and Giddens (1990) refer to as a complex global web of interconnectedness. Korten, (2001), Garfolo and L'Huillier (2014a; 2014b), Maxton (2011), Stiglitz (2010), Kelsey (2002), and Shiva (2000) use the term "globalization" when critiquing capitalism as the dominating form of global development. All agree that globalization fosters significant inequality through intensifying competition as an unrelenting organizing dynamic that serves the interests of the minority elite. And yet despite significant scholarly agreement about the dangers of the prevailing form of globalization we still continue to teach this form of business model to our students as the way forward in terms of global development.

As business educators, the problems associated with the concept of globalization and how to teach it represents a serious ethical dilemma. Unfortunately, experience has shown that for the most part, curriculum designers and faculty counsels in business schools have shied away from this potential political hornets' nest. Rather, they prefer to adopt the Milton Friedman approach to business and social responsibilities by ensuring students are taught how to maximum shareholder wealth by leveraging business opportunities as they arise and how to improve the bottom line (Prahalad, 2004; Prahalad \& Hammond, 2002; Prahalad \& Hart, 2002).

We argue in this paper that education should not only be about knowledge and requisite skills, it should also be about ethical responsibility, not only to shareholders, but to fellow human beings. By sustaining, promoting, and teaching globalization in its current form, educators are not attending deeply enough to the flawed constituent concepts embedded and intensified in discourses of organization, of good governance, and of efficient management. We, as academics and educators, risk simply being one more ripple in the ongoing tide of neo-colonization repackaged and marketed as globalization. As noted by Garfolo and L'Huillier (2014b), globalization does not serve all people equally.

\section{Effects of Globalization}

There is much debate in the literature over the true effects of globalization and it is a concept that can be seen from many different angles. Köhler (2002), managing director of the International Monetary Fund (IMF), describes globalization as an on-going process "through which an increasing flow of ideas, people, goods, services and capital lead to the integration of economics and societies" and results in significant changes to markets and businesses.

As a concept, globalization is an old one. Examples can be seen from when the Silk Road connected East and West (starting during the Han Dynasty) to the more modern cited example of when the Dutch and British East India Company began trading with India. Integrating a global economy is nothing new but its implications are far reaching. Globalization has many redeeming aspects, as its supporters would espouse. For example, through globalization: 
1. There is brand image consistency.

2. Companies get access to more markets.

3. Consumers get more choices for products and prices.

4. Cultural intermingling allowing others to learn more about different cultures.

5. Greater ease and speed of transportation of people and goods.

6. Increased flow of communications.

7. Increased liquidity of capital.

8. Lowers marketing costs.

9. Shared financial interests.

10. There is more information sharing between countries.

However, the present trajectory of global development (globalization), does not match up with the claims that it will transform the lives of impoverished individuals and communities and even whole societies for the better. The reality is the mobilization and exploitation of human and natural resources, a widening of the gap between the rich and poor ultimately resulting in cultural homogenization, and an exacerbation of inequality and social and environmental degradation (Soros, 2002). The worker is viewed simply as a factor of production whose cost is to be minimized in order to improve returns to the investor. It is this concept, this way of looking at humanity and of natural resources, economics, social and cultural norms, and business practices in general, that is nicely packaged and presented in a palatable way to the world and called Globalization (Garfolo \& L'Huillier, 2014b).

If we leave the type and pattern of globalization up to those nations and corporations who are currently promoting this business model, then we risk corrupting the cultural diversity and identity of the countries to which we are marketing our wares (Garfolo and L'Huillier, 2014b). Indeed as noted by Scherer, Palazzo and Matten (2009, p. 330) "the social political engagement of corporations has become a widespread phenomenon".

Arguably, one of the primary driving forces of globalization is capitalism and the driving force in capitalism is the maximization of profit. As globalization deals with global exports, the goal then is to sell as much as you can, export as much as you can while making as much money as you can. In general, according to the messages coming out of business schools, there is nothing wrong or evil about making a profit. Or is there? When social responsibility and ethics are marginalized in business in favour of solely focussing on profit maximization the result is a business model driven by greed and unbridled materialism. Regrettably globalization has become more of a cultural phenomenon effecting how people think, act and behave in society at large (Garfolo \& L'Huillier, 2014b). It has become a wave of commercialism that has washed away cultural points of reference, along with legal and cultural safeguards marching everyone at a steady pace towards a borderless world economy (Scholte, 2005).

The risk of globalization is that it often (and does) breaks down social and cultural lifestyles to be replaced by a new "global" culture and lifestyle. The 
end result of globalization is, in many instances, cultural disintegration (Garfolo \& L'Huillier, 2014b; Cohen \& Kennedy, 2000). Globalization is a slow march toward a universal identity (Niezen, 2004) with the resulting "new" breed of global citizen composed of men and women for whom religion, ethnic nationality and cultural uniqueness are only marginal elements in their newly constructed working identity (Barber, 1996).

We believe that the problem is not so much about globalization, but rather, the type and pattern of it. If we are to accept and even embrace the concept of globalization, then what is needed is globalization driven by ethics built on a philosophical foundation of "equitable treatment for all" with procedures to recognize and resolve ethical dilemmas that arise. Unfortunately, one byproduct of globalization is an observable ethical failure at world level (Singer, 2004; Velasquez, 2000).

\section{Education and Globalization without an Ethical Context}

If we look at universities, specifically business schools world-wide, it would seem that a disproportionate number of them have been emulating a North American style of education. As expected, this produces a rather uniform/generic product - the coveted school of business MBA graduate.

We posit that a generic graduate, possessing a generic education, produces generic business solutions and is ill fitted to address business problems from a global perspective. Yet in every institution investigated in this study the common theme stated in their prospectus was "Globalization", a term that is not well-defined and with different meanings for different groups in both education and business. Often universities include the term "global" in their mission statements in the belief that it demonstrates that they are graduating globally competent students. Globalization is at best a controversial system of global economic development.

In its current form, globalization is generally taught without any serious cultural or historical reference and as such poses a problem. Why? Because we lose sight of the fact that globalization is nothing more than neo-colonialism packaged as a kinder and gentler word (Garfolo \& L'Huillier, 2014a). We are limiting our students' exposure and understanding of the nature and scope of the problem, its economic origins and historical significance and context. We contend that universities have a responsibility and obligation to design and develop curriculum that presents globalization not as a stand-alone concept but rather, as an interdisciplinary topic associated with multiple programs in order to ensure that the concept is viewed from multiple perspectives.

Business schools around the world and North American schools in particular, are becoming more and more aligned with the corporate world. It is therefore hardly surprising that the focus of the curriculum "product" primarily reflects a strong economic component and gives only marginal-to-no-coverage of the historical origins and cultural effects of globalization (neo-colonialism). Many North American schools boast of having a substantial international 
student population and yet many business programs, particularly MBA and EMBA programs rarely, if ever, teach globalization from an international perspective. Full coverage of the topic can only be accomplished from an international and interdisciplinary viewpoint. Eisenstein (2005, p. 487) goes further claiming, "alternatives to capitalism have become devalued and delegitimized".

Business schools are complicit in promoting this devastating global philosophy of economic colonialism (globalization) as we teach our graduates how to most effectively "work" the global markets for the benefit of the wealthy and powerful. When faculty teach these concepts and techniques they are, in actuality, instructing graduates on how to disrupt economic systems and its accompanying culture in developing nations under the guise of trying to interconnect and globalize. Rather than teaching concepts and techniques that are ethical and recognize a responsibility to society, current teaching results in benefits for economically prosperous countries and little-to-no economic benefits for the remainder of the world's population. It seems that in general the drivers associated with globalization lack an ethical component.

As educators and developers of the curriculum currently taught our courses and programs, particularly interdisciplinary courses, should provide students with the skills necessary to think beyond standard economic theories and global supply chain management topics currently covered. Students need to be exposed to the richness and diversity that all cultures have to offer, the historical context and social interactions of people and given opportunities to develop skills needed to address contemporary business issues in a "humane" way. What we ultimately need is to provide an environment for students that promote a "more critical, corrective, holistic, and ethical" way of conducting business (Karenga, 2000, p. 16).

\section{Ethics in Business Education}

Ethics, as a concept, has been well explained in schools around the globe although there is no universally accepted definition. Koehler (2003, p. 99) writes: "ethics are generally perceived to derive from, and serve as, the application of moral principles" and "in their applied form undergo a metamorphous as underlying conditions change". In this context "morals" represent a set of mores, traditions, and customs that may be influenced by social practices or religious beliefs. Ethics is about what is acceptable or unacceptable behavior within a specific group. In general this means ethics is about learning (seeing) what is right or wrong; and then doing (something actionable) the right thing - but the question is "the right thing" for whom?

Due to the fluid nature of ethics there is no generally accepted definition of ethics. Indeed since the time of Socrates and Plato, philosophers have heavily debated the definition of ethics thus it would appear that an individual's understanding of ethics is a personal one. For some, ethics is an ever evolving ever changing "living" concept. What is ethical today is not tomorrow thus 
ethics seems to be largely a matter of perception. Unfortunately, it would also appear that today, many ethicists equate ethical beliefs to legal matters. As such, what is just an ethical guideline today makes itself into the cannons of law tomorrow. Subsequently, the ethical values which should be guiding our daily lives are really nothing more than what happens to be legal at the time. However, it should be noted that there are some ethicists who maintain that there is always a "right thing to do" based on moral principles.

The use of the term "business ethics" has intensified in the last 40 years during the economic and political changes that have swept the world. Business ethics, as a field of study, can be traced to the 1970s (Ferrell \& Fraedrich, 2014). However, it would appear that there is no overarching theory of business ethics and that it is a hotly contested concept with different meanings for different people depending on their ontological preferences. Indeed Lewis (1985, p. 377) wrote "defining business ethics is like nailing Jello to a wall". In essence though, business ethics helps the participant to a) identify ethical issues as they arise and b) to recognize difference approaches available to resolve ethical issues (Ferrell \& Fraedrich, 2014). It is our belief that if a business education does not include a strong, directed approach and coverage of socially responsible business ethics, students will not be equipped to identify and resolve complex ethical business dilemmas.

\section{Methodology}

As ethics and globalization are complex concepts. Our hypothesis is that the problems associated with the current form of globalization lies within the business school curriculum and the integration of the nature and type of ethics courses offered. To examine this hypothesis, we gathered and reviewed the course offerings of 400 business school MBA programs in the United States and internationally all of whom is either Association to Advance Collegiate Schools of Business (AACSB) or Accreditation Council for Business Schools and Programs accredited. From this sample of 400 business schools, we randomly selected $50 \mathrm{MBA}$ programs and undertook an in-depth curriculum review of both their program and their published Student Learning Outcomes (SLO's). The questions posed in our examination of the MBA programs were simple and straightforward:

1. Is an ethics course a required part of the MBA core curriculum?

2. Is an ethics course offered as an elective in the MBA curriculum?

3. Is the MBA program without an identified course in ethics?

4. If an ethics course is included in the MBA program as either a core course or elective course, what was the nature/type of the ethics course offered? 


\section{Findings}

Figure 1 shows the number of schools requiring courses related to ethics and the type (classification) of ethics courses offered.

Figure 1. Breakdown of Ethics Courses Required as Part of the Core Curriculum

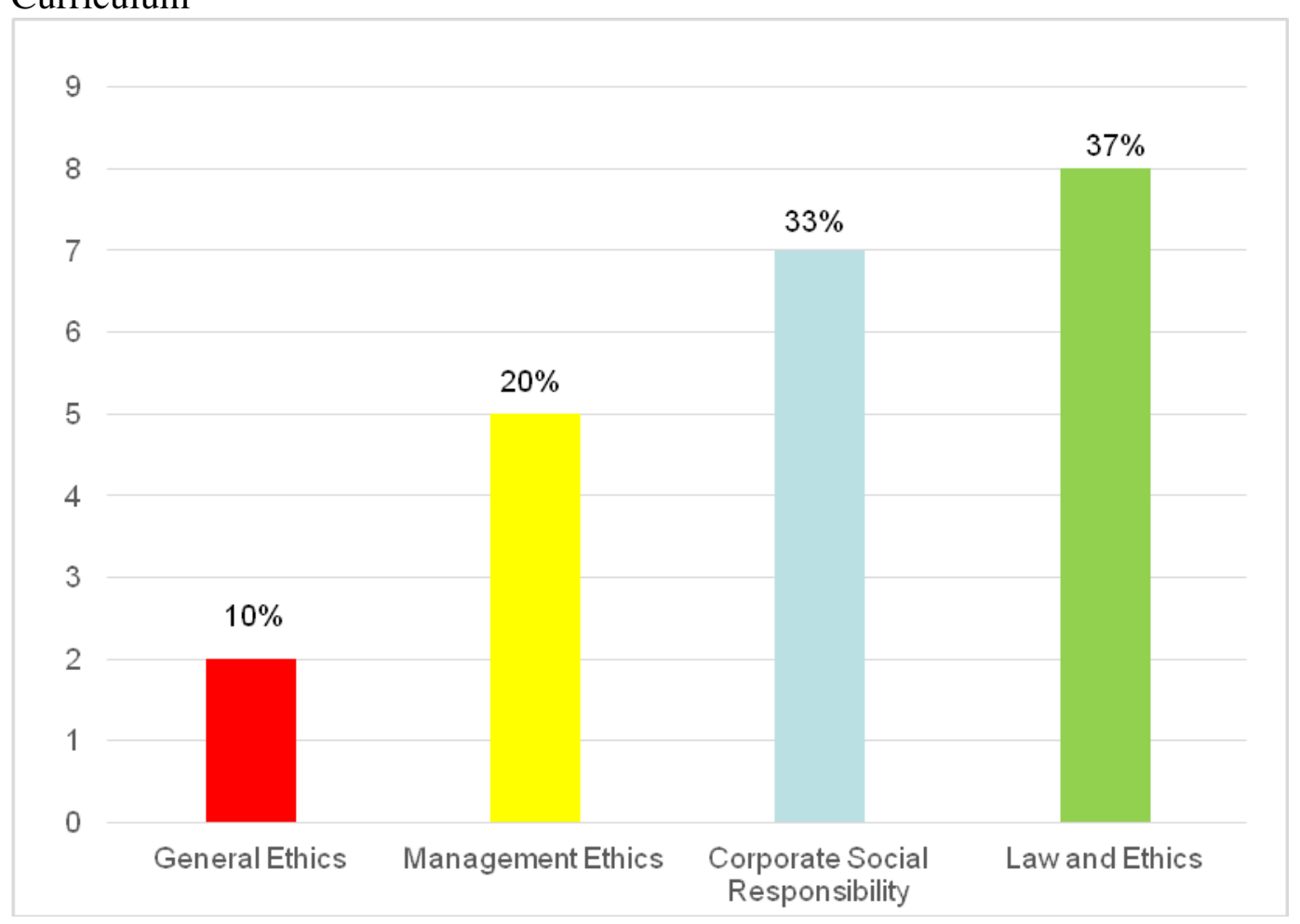

In the study it was discovered that only $44 \%$ of the universities examined $(22 / 50)$ required an ethics course in their core curriculum and $52 \%$ of the universities sampled (26/50) offered an ethics course as an elective only, not as a core course (Figure 2). Finally, 4\% of the universities examined (2/50) offered no ethics courses either as a core course or elective. Taking a pessimistic view, it is possible from this random sample of 50 MBA programs for $56 \%$ of business students to complete their university degree and graduate with an MBA with not having taken a single course on ethics. Worse yet, $4 \%$ of graduates are not even given the opportunity in their program of study to take an ethics course. 
Figure 2. Summary of Ethics Course Requirements

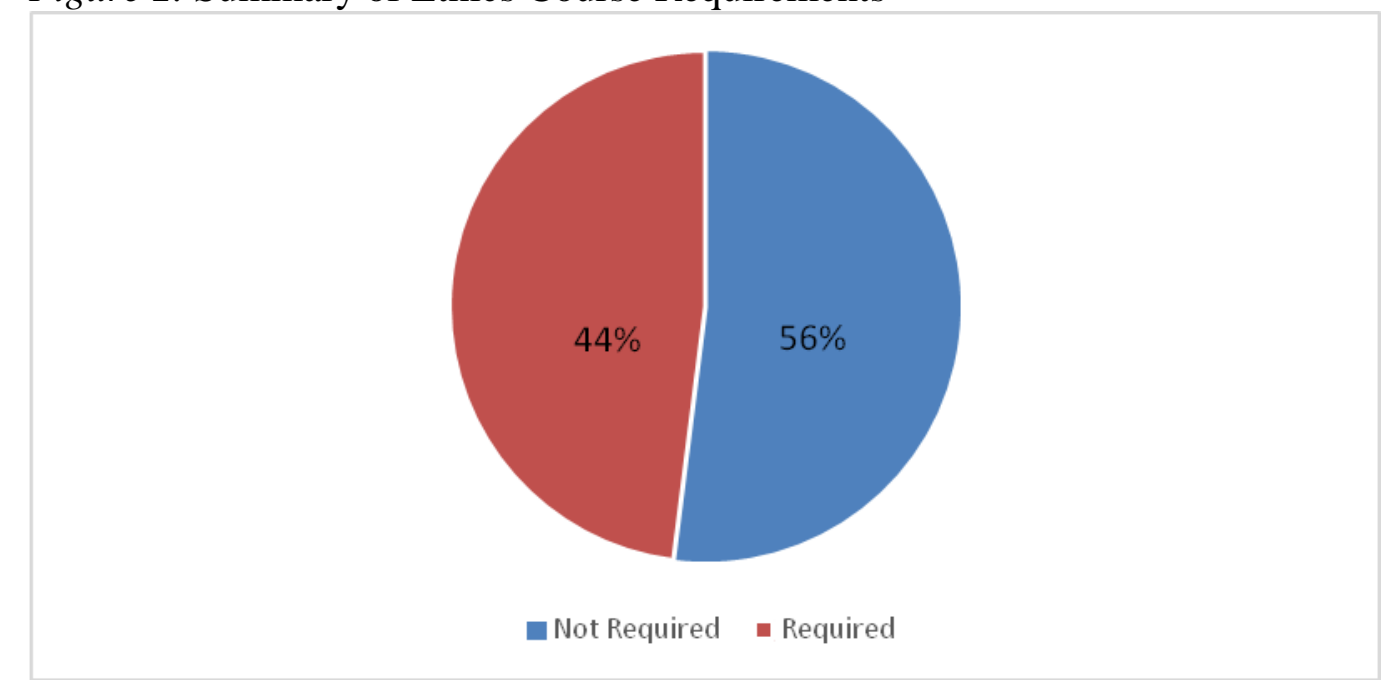

Upon further investigation, it was discovered that the justification for not offering an ethics course as a required part of the student's business core curriculum was that the universities believed an ethics component was woven into the program through its courses. As such, they did not offer a specific course in ethics. However, upon review of their Student Learning Outcomes (SLO's), it was noted that not one of the universities had "ethics" as a component of their Student Learning Outcomes.

As noted by Garfolo, Kelpsh and Phelps (2015) and Garfolo and L'Huillier (2015) to be an effective Student Learning Outcome it must be: achievable by the learner; observable; measurable and should be meaningful to the discipline (Ivanovski, Milenkovski, \& Kozuharov, 2013). By not including a course in ethics or making ethics a part of Student Learning Outcomes (SLOs) university administrators have, in essence, stated that the concept was not meaningful to the discipline and not worthy of measurement. If we cannot measure a SLO how will we know if the concept was understood?

\section{Discussion}

We are not arguing in this paper that universities and business programs do not develop/graduate ethical leaders, quite the contrary. They can and do develop ethical leaders and we acknowledge their contributions to building a better society. Unfortunately, the scandals at Enron, Home State Savings Bank, Midwest Federal Savings and Loan, Lincoln Savings, Silverado Savings and Loan, Tyco, WorldCom and many other companies clearly demonstrate that failures in ethical leadership continue to plague organizations worldwide (Lindsey \& Petit, 2008). Ethics and a moral compass are critical for our leaders, both current and future, and the role business schools play in developing our graduates is vital. While we acknowledge that many business schools have inserted ethics into their programs, this retrofit approach often 
relegates ethics to the role of an add-on component to an already established program rather than as an integral part of it.

The traditionally emphasized skills in a business school's curriculum such as finance, statistics, operations management, and information technology currently dominate and overshadow the much needed concepts of selfawareness, ethics and holistic values (Lindsey \& Pate, 2006). As North American universities become, through donations, sponsorships and endowments, more tightly connected to the corporate world order, it should come as no surprise to anyone that globalization courses with its emphasis on high economic content are highly sought after. What is needed is for our institutions, both at the graduate and undergraduate level, to develop programs that incorporate the themes of Corporate Social Responsibility, Leadership and Ethical Decision Making within frameworks of their respective programs. As this study reveals it is entirely possible for $56 \%$ of MBA graduates to obtain their degree without ever having attended a class on ethics, ethical responsibility or even ethical awareness.

If the goal of education is to develop and enlighten the minds of students, provide opportunities for character-building, and broaden their respective visions then as educators we must teach ethical awareness and ethical leadership. Educators must understand the critical role they play in achieving this goal. In addition, the education system must keep pace with the rapid technological changes we experience daily and the role it plays in globalization (Pandey, 2001). As educators we have a unique window of opportunity to help mould and graduate leaders that are committed to adhering to a set of ethical and moral principles in their decision-making process despite the temptations around them (Lindsey \& Pate, 2006).

In the wake of the scandals mentioned earlier what we do not need is more rules-based guidelines to cover every possible human failing. Rather, what is needed are graduates (leaders) of ethical integrity; graduates who have been taught how to recognise ethical dilemmas and what options are available to resolve them and more importantly, an awareness of how their actions will affect the lives of others (Lindsey \& Pate, 2006). As educators, especially in business schools, it rests upon us to engage our students and help them to define what a "long-term" vision of success is and where this "vision" is built on a strong ethical foundation.

It is not a coincidence that globalization courses are on the rise in many universities and colleges in North America. Unfortunately, these courses, even though many are of an interdisciplinary nature, are handicapped by a predominant economic framework and are increasing in number in parallel with the rise in globalization. If we are to broaden the understanding of our graduates, we must take corrective action in the teaching of our courses on globalization by raising ethical awareness of the resulting cultural disintegration and dehumanization that is currently a by-product of today's global business model approach (Garfolo \& L'Huillier, 2014b).

Our research indicates that $33 \%$ of the universities examined looked at ethics from a social responsibility viewpoint (refer Figure 1) i.e. what is the 
ethical responsibility of the corporation to society at large? We suggest that corporate social responsibility is the vehicle with which to equip our MBA students with the knowledge and ethical awareness to assist them in becoming good stewards not only of their corporations' assets and profits but of the community at large. Based on our research findings we conclude that our hypothesis is upheld and that many of the problems associated with the current form of globalization lies within the business school curriculum and the integration of the nature and type of ethics courses offered.

Exposure and understanding of a variety of cultural, environmental, and economic issues is paramount if we are to attain the goal of graduating a global citizen as the new breed of corporate manager. But, in order to achieve this goal the message coming from our institutions of higher learning, especially schools of business, must be clear and unambiguous emphasizing the value of humanity. People, regardless of their culture, location or social order, must be at the centre of the decision-making process. People must not be the means to an end. Rather, they should be valued and respected which is their inalienable human right.

Globalization (the new economic colonialism) and the negative consequences on cultures in the developing world has become perhaps the most significant force in promoting the cultural identity of the dominant player(s) in the market place - the economic master. It is clear that the version of globalization we teach our students, to dominate world markets through a unique blend of capitalism and Westernization, is responsible for the erosion and elimination of traditions and cultures throughout the world and should not be allowed to continue in its current form. Globalization must be taught from the point of view of the manifestation of human freedom and respect for life.

\section{Conclusion}

Globalization is packaged as the hope and promise of increasing prosperity and the development of opportunities for all but the reality is quite the opposite in many instances. As a business model, globalisation is increasingly been held up as one of the key elements in the exploitation of human and natural resources and the widening of the gap between the rich and poor and of the proliferation of social and environmental degradation.

Globalization must be taught in such a way as to get students to start questioning its process, usage and proliferation. Students need to become aware of the cultural disintegration that stems from the way globalization is currently implemented. Cultural awareness, hidden assumptions and the differences between wants and needs should be a major component in teaching globalization. It is the obligation and duty of educators to provide students with the ability to understand the global consequences of not being responsible to society.

As educators, our role is to provide a context or framework that allows students to become aware of their core values, the convictions and beliefs that 
they have that will influence the how's and why's of their decision-making process. As educators, we must expose our students to a variety of ethical dilemmas they could potentially face and guide them in their search for solutions that are compatible with their responsibilities to society and to the corporate world.

\section{References}

Barber, B. R. (1996). Jihad vs. McWorld: How globalism and tribalism are reshaping the world. New York: Ballantine Books.

Beck, Y. (2000). What is Globalization? Cambridge: Polity Press.

Bourdieu, P. (1998). Acts of resistance: against the tyranny of the market. New York: Dutton.

Cohen, R., \& Kennedy, P. (2000). Global Sociology. London: Macmillan.

Deetz, S. (1992). Democracy in an Age of Corporate Colonization: Developments in Communication and the Politics of Everyday Life. S Albany: State University of New York.

Eisenstein, H. (2005). A dangerous liaison? Feminism and corporate globalization. Science and Society, 487-518.

Ferrell, O. C., \& Fraedrich, J. (2014). Business ethics: Ethical decision making and cases. Boston, MA: Cengage Learning.

Garfolo, B. T., \& L'Huillier, B. M. (2014a). Economic Colonialism: The New Empire Building of the 21st Century. Academy of Business Journal, 1, 48-55.

Garfolo, B. T., \& L'Huillier, B. M. (2014b). Ethics, globalization and cultural disintegration. International Journal of Arts and Sciences, 7(2), 585-592.

Garfolo, B, T., Kelpsh, E., \& Phelps, Y. (2015). Authentic Programmatic Assessment: A Straightforward Path to Accreditation. Academy of Business Journal, 1, 6-30.

Garfolo, B. T., \& L'Huillier, B. M. (2015). Programmatic Assessment: The Road to Accreditation. Journal of College Teaching and Learning, 12(4), 151-170.

Giddens, A. (1990). Consequences of modernity. Cambridge: Polity Press.

Held, D., McGrew, A., Goldblatt, D., \& Perraton, J. (1999). Global Transformations. Stanford CA: Stanford University Press.

Ivanovski, Z., Milenkovski, A., \& Kozuharov, S. (2013). Development and improvement of business higher education through implementation of Students Learning Outcomes Asessment Plan (SLOAP). UTMS Journal of Economics, 4(1), 1-16.

Karenga, M. (2000). Black studies: A critical reassessment. In Dispatches from the ebony tower: Intellectuals confront the African American experience, $\mathrm{M}$. Marable, 162-170. New York: Columbia University Press, 2000.

Kelsey, J. (2002). At the crossroads: Three essays. Wellington, New Zealand: Bridget Williams Books.

Koehler, W. (2003). Professional Values and Ethics as Defined by " The LIS Discipline". Journal of Education for Library and Information Science, 99-119.

Köhler, H. (2002). Working for a better globalisation. International Monetary Fund. Retrieved from http://bit.ly/2h10WE6.

Korten, D. C. (2001). When corporations rule the world $\left(2^{\text {nd }}\right.$ ed). San Fransisco: Berret-I Koehler.

Lewis, P. V. (1985). Defining "business ethics": Like nailing jello to a wall. Journal of Business Ethics, 4(5), 377-383. 
L'Huillier, B. M. (2013). The Key to "Business Success". Accounting, Auditing and Accountability Journal, 26(6), On-line version

Lindsey, W., \& Pate, L. (2006). Integrating Principle-Centered Leadership into the Business Curriculum: Lessons from the LMU Experience. Journal of Executive Education, 5(1), 17-29.

Lindsey, W., \& Petit, F. (2008). Jesuit executive MBA programs: Building a just society. Business Renaissance Quarterly, 3(3), 107.

McGrew, A. (2005). The globalization of world politics. UK: Blackwell Publishers.

Maxton, G. (2011). The end of progress: How modern economics has failed us. Queensland, Australia.

Niezen, R. (2004). (Anti) Globalization from below. In A World beyond Difference: Cultural Identity in the Age of Globalization, pp. 57-81. Malden, MA: Blackwell.

Pandey, V. C. (2001). Education and globalization. Delhi: Kalpaz Publications.

Portes, A. (2000). Globalization from below: the rise of transnational communities. The ends of globalization: bringing society back in. Maryland: Rowman and Littlefield Publishers.

Prahalad, C. K. (2004). The Fortune at the bottom of the pyramid: Eradicating poverty through profits. Upper Saddle River, NJ: Wharton School Publishing.

Prahalad, C. K., \& Hammond, A. (2002). Serving the world's poor, profitably. Harvard Business Review, 80(9), 48-59.

Prahalad, C. K., \& Hart, S. L. (2002). The fortune at the bottom of the pyramid. Strategy + Business, 26, 2-14.

Scherer, A. G., Palazzo, G., \& Matten, D. (2009). Introduction to the special issue: Globalization as a challenge for business responsibilities. Business Ethics Quarterly, 19(03), 327-347.

Schölte, J. A. (2005). Globalization: A Critical Introduction (2 ${ }^{\text {nd }}$ ed) New York: Palgrave.

Shiva, V. (2000). Globalization and poverty. Resurgence, 202. Retrieved from http://bit.ly/2hhj9Lv.

Singer, P. (2004). One world: The ethics of globalization. New Haven: Yale University Press.

Soros, G. (2002). George Soros on globalization. New York: Public Affairs.

Stiglitz, J. (2010). Why we have to change capitalism. Retrieved from http://bit.ly/1c6QLGB.

Velasquez, M. (2000). Globalization and the failure of ethics. Business Ethics Quarterly, 10(1), 343-352. 